\title{
Margarita Práxedes Muñoz: una de las adelantadas del feminismo peruano
}

\author{
Margarita Práxedes Muñoz: one of the advanced of Peruvian feminism
}

\author{
Ricardo Iván Álvarez-Carrasco ${ }^{1}$
}

\section{Resumen}

María Margarita Magdalena Muñoz Seguín, mejor conocida como Margarita Práxedes Muñoz, fue una mujer polifacética y una de las pioneras del feminismo, el positivismo y de los estudios universitarios en el Perú; además, de la masonería en Sudamérica y autora de una extensa producción literaria y científica. Sin embargo, su vida y obra han permanecido desconocidos entre nosotros, por lo que se esboza una semblanza biográfica de este personaje tan trascendente y casi inédito.

Palabras clave: Historia, literatura, feminismo, universidad, siglo XIX.

\section{Abstract}

María Margarita Magdalena Muñoz Seguín, better known as Margarita Práxedes Muñoz, was a multifaceted woman and one of the pioneers of feminism, positivism and university studies in Peru; in addition, freemasonry in South America and author of an extensive literary and scientific production. However, her life and work have remained unknown among us, so a biographical semblance of this transcendent and almost unprecedented character is sketched.

Keywords: History, literature, feminism, university, 19th century.

\section{Introducción}

La investigación de la vida y obra de Margarita Práxedes Muñoz constituye un auténtico reto, con algunas pocas excepciones, las referencias

Médico patólogo clínico. Asociación de Historia de la Medicina Peruana. Academia Panamericana de Historia de la Medicina. Instituto Nacional Materno Perinatal, Lima, Perú.

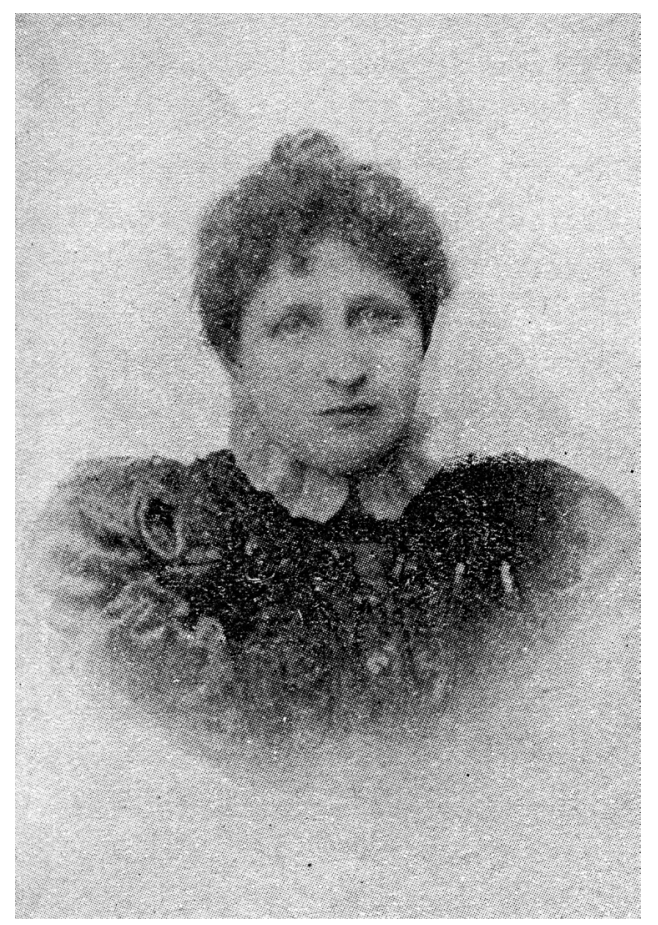

Margarita Práxedes Muñoz. Imagen publicada en el segundo tomo de la obra La mujer peruana a través de los siglos de Elvira García y García (Lima, 1925). biográficas son escuetas, dejan vacíos significativos, y están centradas fundamentalmente en su producción literaria y militancia en el positivismo. 


\section{Antecedentes sobre el derecho de las mujeres a la educación}

La revolución francesa marcó el inicio de la individualidad y la ciudadanía, las mujeres empezaron a demandar su acceso a la educación con la certeza que ello significaría un cambio en su situación, aunque no cuestionaron las estructuras de la sociedad; posteriormente, exigieron la instrucción que les permitiera acceder a un trabajo para su manutención, que implicaría la autonomía y por tanto la puerta de la liberación. ${ }^{1}$

En Latinoamérica el acceso femenino a la educación universitaria se inició en la década de 1870 , teniendo la profesión médica un rol protagónico ${ }^{2}$; y, en 1877 la colombiana Ana Galvis Hotz se doctoró en la Universidad de Berna, Suiza, siendo la primera médica de su país e Hispanoamérica. ${ }^{3}$

En 1886 Eloísa Díaz Insunza fue la primera chilena que se tituló de médico cirujano en la Universidad de Chile ${ }^{4}$, en mérito al decreto del 5 de febrero de 1877, por el "que las mujeres deben ser admitidas a rendir exámenes válidos para obtener títulos profesionales, con tal que se sometan para ello a las mismas disposiciones a que están sujetos los hombres"5, dicho suceso aparentemente lejano al Perú tendría una gran trascendencia en la vida de Margarita.

En los primeros años de la República, el Estado peruano planteó la incorporación de los sectores excluidos de la ciudadanía y la educación se convirtió en un instrumento idóneo para tal propósito ${ }^{6}$; el 6 de octubre de 1825, el Consejo de Estado mandó a establecer un gineceo, una escuela para niñas, en el convento de la Concepción de Lima ${ }^{7}$; en 1836 se creó la Escuela Normal de Mujeres en el convento de Santa Teresa de Lima; y, luego se establecieron escuelas primarias femeninas y colegios nacionales gratuitos para mujeres en cada provincia del país. ${ }^{6}$
En la segunda mitad del siglo XIX predominaba la idea que los conocimientos académicos e intelectuales conducirían a las mujeres a desdeñar las cualidades inherentes a su sexo y las convertirían en hombres ${ }^{6}$; sin embargo, surgiría la primera generación de peruanas ilustradas que exigió el acceso a la instrucción ${ }^{1}$; así, en 1866 la educación primaria se hizo obligatoria para hombres y mujeres, aunque la secundaria siguió siendo exclusiva de los varones. $^{8}$

Por entonces era una osadía que una peruana pretendiera ingresar a la universidad. La Universidad de San Marcos tenía un carácter eminentemente conservador y antepuso una especie de barrera para la mujer, suponiendo que al profundizar en sus estudios corría el riesgo de debilitar su fe; y, para mantenerla en el culto exclusivo del hogar y en su obediencia sumisa al hombre, debía ser un tanto ignorante. ${ }^{9}$

Retando estas ideas apareció la extraordinaria figura de la cusqueña María Trinidad Enríquez Ladrón de Guevara, quien consiguió la dación de la resolución suprema del 3 de octubre de 1874, que la autorizó a matricularse en la universidad del Cusco ${ }^{6,9}$, convirtiéndose en la primera peruana en realizar estudios superiores, que concluyó tres años después, recurriendo al Congreso Nacional para obtener el grado académico, gestión que quedó suspendida por el inicio de la Guerra del Pacífico y se reinició en 1886, cuando dicho Congreso derivó su pedido a la Corte Superior de Lima, instancia que finalmente le negó el bachillerato. ${ }^{6}$

Luego de la Guerra del Pacífico (1879-1883) las necesidades económicas fueron apremiantes, esa profunda crisis estimuló a las mujeres ilustradas, muchas de ellas viudas durante aquella guerra, a tener una vida pública, clave en la génesis del movimiento liberal social que fue crítico y mordaz con la oligarquía, a la que responsabilizó de la derrota y la amputación territorial. ${ }^{10}$ Ello constituyó 
el catalizador para exigir el acceso de las féminas a todos los niveles de instrucción.

\section{El nacimiento de Margarita y los primeros años de vida}

En su partida de bautismo, conservada en el Archivo Arzobispal de Lima (Folio 83 del Libro de bautizos españoles de la Parroquia de San Sebastián de Lima 1848-1852), se consigna que nació en la ciudad de Lima, el martes 18 de julio de 1848, siendo sus padres José Muñoz y María Seguín.

Por entonces gobernaba Ramón Castilla, era la época del fugaz auge por la explotación del guano y el salitre, que permitió constituir las bases del Estado peruano moderno. Las revoluciones y los golpes de Estado encabezados por militares eran moneda corriente, al punto que dicho presidente fue el primero que completó su período gubernamental. El domingo 18 de marzo de 1849 era bautizada a los ocho meses de edad, en la parroquia de San Sebastián, de Lima, con los nombres María Margarita Magdalena, siendo su madrina María López Salazar y atestiguando el sacramento José Aponte y Juan Puente, según figura en la partida antes citada.

$\mathrm{Su}$ familia materna estuvo ligada a la vida política y al quedar huérfana a temprana edad fue criada por ella, bajo una antigua tradición liberal $\mathrm{y}$ laicista. ${ }^{2,11,12}$ De Lucía refiere que su abuelo era don Juan Salazar, pero esta referencia, salvo alguna explicación plausible, no coincide con el apellido de su madre. ${ }^{12,13}$

\section{La relación con las primeras feministas peruanas}

Asistió a las célebres veladas organizadas por Juana Manuela Gorriti, entre 1876 y 1877, dicha escritora argentina vivió en Lima por varias temporadas, entre 1840 y 1880, estableciendo una escuela femenina infantil, en la calle Urrutia - hoy séptima cuadra de jirón Camaná-, que también era utilizada para tales veladas, a las que asistieron Mercedes Cabello, Manuela Villarán, Carmen Pots, Juana Manuela Lazo y su hija, Carolina y Justa García Robledo, Juana Rosa Amezaga, Leonor Saury, Ariana Buendía, Cristina Bustamante, Isabel Eléspuru, Mercedes Ovalle, Ubalda Plasencia y Manuela Cabello entre otras. ${ }^{14,15-17}$ Clorinda Matto, que vivía en el Cuzco, visitó Lima por primera vez en 1877, siendo recibida cálidamente por Gorriti, con quien entabló una profunda amistad. ${ }^{18}$

Gorriti no fue la típica mujer decimonónica, abandonó a su marido, el general Manuel Isidoro Belzú, cuando aquel llegó a la presidencia de Bolivia, en 1848; prosiguió por cuenta propia una carrera literaria en Lima, tuvo dos hijos fuera del matrimonio, sirvió como enfermera en el combate del 2 de mayo de 1866, y en su afán de vengar el asesinato de su esposo pretendió dirigir un ejército en tierras altiplánicas. ${ }^{14,15}$ Es probable que su novelesca vida impresionara hondamente el espíritu de Margarita y le sirviera de inspiración para el resto de su existencia.

En esas veladas inició su estrecha relación con las fundadoras del movimiento feminista en el Perú, algunas próximas a la masonería que, aunque no incorporó mujeres, les permitió participar en ciertas veladas, en las que se ocurrían debates científicos, literarios, religiosos y otros, a los que concurrieron Mercedes Cabello -cuyos hermanos pertenecían a esta hermandad-, Clorinda Matto, y Zoila Aurora Cáceres, quienes asumieron una posición de avanzada al abandonar el ámbito doméstico para ejercer el periodismo y la literatura, denunciando la ideología de los grupos de poder tradicionales, en especial la iglesia católica. ${ }^{19,20}$

\section{Los estudios en la Universidad Mayor de San Marcos}

Según Quiroz, en 1882, en pleno cautiverio de Lima, se matriculó en la Facultad de Letras de la Universidad Mayor de San Marcos, convirtiéndose 
en la primera mujer que estudió en la universidad decana de América, cursando en el primer año psicología y lógica, literatura general y literatura antigua, entre otras materias. ${ }^{6}$ En 1883 se volvió a matricular, pero no concurrió a las clases, sin embargo sería la primera vez que utilizó el nombre Práxedes, por su admiración al gran maestro masón español Práxedes Mateo Sagasta. ${ }^{21}$

El 30 de abril de 1888, casi a los cuarenta años de edad y desistiendo de casarse, se matriculaba en la Facultad de Ciencias de la misma universidad, luego de obtener la dispensa del examen general de instrucción media que exigía el reglamento del ramo a los aspirantes universitarios. ${ }^{6,8,22}$ En este trámite consignó como domicilio la calle de los Huérfanos $\mathrm{N}^{\circ} 106$, hoy sétima cuadra del jirón Azángaro del Cercado de Lima, el mismo que había señalado en 1882, y que estaba muy cercano al antiguo local del Convictorio de San Carlos, hoy conocido como la Casona de San Marcos, donde funcionaba dicha Facultad. ${ }^{17,21}$

$\mathrm{Su}$ presencia en San Marcos produjo desconcierto entre las autoridades y catedráticos, su "caso se prestaba a muy variados comentarios, por la novedad que llevaba consigo, y los mismos profesores, no se decidían por la actitud, que les correspondía tomar. Rechazarla no era posible, porque no había ley en que fundar ese rechazo. Aceptarla, era un problema cuya solución no sabían adonde había de conducirlos". 9

Por entonces su pensamiento estuvo dominado por las ideas del positivismo, preconizado por el francés August Comte y el británico Herbert Spencer, que cimentó firmemente su creencia en la igualdad entre el hombre y la mujer, que no tenían diferencias biológicas, sino de carácter social. ${ }^{23}$

Seguramente conoció a Federico Villarreal, maestro de dicha Facultad y uno de los primeros positivistas del país; y, también a Sebastián Barranca, antiguo maestro de esa corporación, que ejerció la docencia entre 1866 a $1905 .^{22,24}$

En la matrícula de 1889 señalaba como domicilio la calle de los Sauces, hoy tercera cuadra del jirón Jauja en el Cercado de Lima, cerca al convento de Santa Clara. ${ }^{21}$ Entre el primer y segundo año de estudios llevó los cursos de física general (nota 11), teorías analíticas fundamentales (nota 10), física general: magnetismo, electricidad, calor (nota 10), química general orgánica (nota 16), y química analítica cualitativa (nota 11$){ }^{21}$

El 18 de diciembre de 1889 solicitaba al decano de la Facultad de Ciencias que, en vista que había aprobado los dos primeros años de estudios, dispusiera que se llevara a cabo la actuación donde sustentaría la tesis de bachiller. ${ }^{21}$

El 16 de mayo de 1890, antes de alcanzar aquel grado, Margarita pidió al gobierno de Andrés A. Cáceres le concediera una pensión de gracia para continuar su instrucción en la Facultad de Medicina de San Fernando, así, el consejo de ministros votó a favor de aquella solicitud, en virtud de ello resolvió "que la Tesorería General abone mensualmente á Da. Margarita Práxedes Muñoz la pensión de cuarenta soles con el objeto indicado; aplicándose el gasto a la partida 271, pliego $3^{\circ}$ del Presupuesto General, en la que existe sobrante suficiente para este egreso; debiendo darse cuenta de esta resolución a la próxima Legislatura". ${ }^{25}$

El viernes 24 de octubre de 1890, sustentó la tesis "Unidad de la materia o identidad sustancial de los reinos inorgánico y orgánico”, que era aprobada por la mayoría del jurado con la nota de once y con la que alcanzó el grado de bachiller. Este trabajo lo dedicó a Mercedes Cabello: "fruto fue de vuestra elocuente pluma mi primera inspiración, justo es que la mía os ofrezca hoy su primer ensayo". Luego, dirigiéndose al jurado, señaló que de esta manera la mujer empezaba a emanciparse de la ignorancia a la que había estado sometida, ensanchando sus horizontes para cumplir su nuevo destino. ${ }^{6}$ La tesis se publicó ese año en la Revista 
Masónica del Perú y como un folleto editado por la imprenta de Juan M. Gall y compañía. ${ }^{26,27}$

La revista El Perú Ilustrado, cuya directora redactora era Clorinda Matto, glosaba este histórico acto en los siguientes términos: "En la tarde del 24 ha dado la Universidad de Lima un paso más en la senda de los progresos, confiriendo el bachillerato a la contraída e inteligente señorita Muñoz, cuya lucida tesis sobre la unidad de la materia bajo el punto de vista químico, fue sustentada con brillo. Felicitamos con toda efusión a la señorita Muñoz, la primera en el Perú que obtiene el diploma de Bachiller, pues a la señorita Trinidad M. Enríquez se la negó, no obstante sus aptitudes y sobresalientes estudios, malogrando tal vez una gloria nacional". ${ }^{28}$ Este logro académico no le granjeo el respeto de los varones contemporáneos, incluso algunos pretendieron descalificarla masculinizándola por el timbre de su voz y el nombre Práxedes que había adoptado; ello también fue una paradoja jurídica, pues la ley peruana aún no autorizaba el ingreso de las féminas a las universidades. ${ }^{22}$ Esta graduación provocó una controversia más allá del ámbito académico, así un seguidor del partido clerical objetó la capacidad intelectual de la sustentante, y otro del liberal, bajo el seudónimo de T. Ófilo, criticaba al clero por pretender mantener a la mujer en la ignorancia con el fin de evitar la propagación de las ideas liberales entre la prole. ${ }^{29}$

Al día siguiente de obtener el bachillerato, el Congreso Nacional aprobaba la pensión de gracia que le había concedido el gobierno para seguir estudios de medicina, la cual ya había recibido efectivamente durante los meses de junio y setiembre de aquel año..$^{30,31}$

En junio de 1890 se le había admitido en la Sociedad Médica Unión Fernandina, en virtud a que "se ha dedicado con verdadera vocación a los estudios médicos, adelantándose a las demás de su sexo que, atraídas por las delicias del hogar y los afectos puros de la maternidad, no creen que, entre nosotros, haya llegado la hora de abandonar el rol poético que les corresponde en la vida de la sociedad, para entregarse a la labor prosaica de la experimentación científica". ${ }^{32}$ Fue la primera mujer que formó parte de esta agrupación estudiantil.

\section{Viaja a Chile y efectúa estudios médicos}

Margarita deseaba continuar sus estudios científicos, siendo la medicina el siguiente paso en su exitosa carrera, pero la intolerancia y misoginia reinantes en el contexto social peruano y la carencia de leyes que permitieran el acceso igualitario de las mujeres a los estudios universitarios, la llevaron a plantearse la necesidad de emigrar a Chile para efectuar tales estudios. $^{5}$

Según Glave, se auto exilió en Chile, huyendo de la pobreza y la violencia familiar, que era ejercida por un marido cuya identidad no menciona, y no se ha podido establecer si contrajo matrimonio o fue madre soltera, sólo se sabe que tuvo una hija llamada Aspacia Muñoz. 12,13,33

El general Andrés A. Cáceres estaba relacionado con el entorno de Margarita y ligado a la masonería, por lo que no fue de extrañar que durante su régimen (1886-1890), se le concediera la pensión antes señalada ${ }^{18,34}$; sin embargo, el 5 de diciembre de 1890 se le revocó este beneficio, porque era contrario a la ley promulgada cuatro días antes, que abolía todas las asignaciones de gracia concedidas hasta esa fecha, y Cáceres estimó "que hacer una excepción en las actuales circunstancias económicas del país no sería de estricta justicia, cuando los pensionistas apenas perciben una tercera parte de sus haberes". ${ }^{30}$ Al día siguiente, Francisco Gerardo Chávez, ministro de Justicia, Culto, Instrucción y Beneficencia, remitía esta decisión al Congreso de la República para que tomara "en consideración lo expuesto y adoptar la resolución que estime conveniente". ${ }^{30}$ 
En vista de esta revocatoria, la Junta de Beneficencia de la Gran Logia del Perú resolvió concederle el apoyo financiero para realizar sus estudios médicos, pues vio en ella un ejemplo que debía ser seguido, para que "venciendo preocupaciones ridículas en nuestros días, buscase la muger en el ejercicio de las profesiones científicas una posición honrada e independiente en la sociedad". ${ }^{27}$

Margarita viajó a Chile hacia fines de 1890, siendo testigo de la caída del gobierno progresista de José Manuel Balmaceda, quien se trabó en una amarga controversia con el Congreso Nacional, que provocó una breve pero sangrienta guerra civil, la que tuvo como dramático corolario el suicidio del referido mandatario, en setiembre de 1891. ${ }^{13,27}$ Tiempo después, nuestra biografiada le dedicó a Balmaceda algunos comentarios en artículos periodísticos. ${ }^{13}$

Asistió como alumna oyente en la Facultad de Medicina de la Universidad de Chile, donde encontró el ambiente propicio para desarrollar sus potencialidades académicas., ${ }^{2,11,22}$ Poco tiempo después empezó a laborar como auxiliar en la Clínica de Enfermedades Nerviosas del doctor Augusto Orrego Lucco, padre de la neuropsiquiatría chilena, donde tuvo el primer acercamiento con esa especialidad, que sería la que dominó el resto de su ejercicio profesional. ${ }^{12}$

En 1894 publicaba el artículo "Diferencias en el volumen craneoscópico de los dos sexos”, en la revista chilena Biblioteca Republicana, en el que refutaba la teoría que sostenía que las mujeres eran intelectualmente inferiores a los hombres por el menor tamaño de sus cráneos; así alzó su voz en una controversia científica con el fin de defender los derechos de las mujeres, empleando el método de legitimación científica al servicio de un objetivo que iba más allá de la ciencia. ${ }^{35}$

En 1893 había publicado la novela La evolución de Paulina, cuya primera edición se tiró en la imprenta Cervantes de Santiago de Chile ${ }^{34}$, muy pocos ejemplares llegaron a Lima, una de sus pocas lectoras sería Mercedes Cabello, quien la alabó por su originalidad en una extensa reseña publicada en la revista El Perú Artístico, que vio la luz el 1 de junio de $1894 .{ }^{22}$ Aquel libro empezaba con una dedicatoria al "ilustre general peruano señor don Andrés Avelino Cáceres", que confirmaba sus afinidades políticas. ${ }^{21}$

La protagonista de la novela era Paulina, el alter ego de Margarita, quien escribía una carta a su amiga Estela en la que, teniendo como telón de fondo la Guerra del Pacífico, relataba su tumultuosa vida y denunciaba la situación de iniquidad en la que vivían las peruanas. ${ }^{22,34}$ Sobre la guerra decía que "los chilenos, no contentos con sembrar por doquiera la desolación y la muerte, no contentos todavía con el saqueo y pillaje de Chorrillos, Miraflores y Barranco han entregado a las llamas estas pintorescas poblaciones", y criticaba ácidamente al general Mariano Ignacio Prado y a su sucesor Nicolás de Piérola. ${ }^{22}$ Ello requería de una gran valentía considerando que residía en Chile. La segunda edición del libro aparecería en Buenos Aires, en 1897.

Se incorporó a los círculos intelectuales y políticos de vanguardia en Santiago de Chile; la experiencia intelectual más importante fue su vinculación con el Apostolado Positivista orientado por los hermanos Juan y Enrique Lagarrigue; y, años después recordaría la gran importancia de sus reuniones con los comtianos santiaguinos, entre ellos los doctores Lattaste y Benavente y el diputado Guillermo Puelma Tupper. ${ }^{13}$

No se ha documentado si alcanzó el grado de bachiller y/o título de médico cirujano en la Universidad de Chile, y obviamente tampoco se halló la tesis correspondiente, lo cual no implica necesariamente que no los haya obtenido. 
El martes 19 de marzo de 1895, Cáceres era depuesto por Nicolás de Piérola, su acérrimo adversario político, cuyo gobierno fue contrario a todos los partidarios y cercanos de su antagonista. ${ }^{36}$

\section{Migra a la Argentina donde vivirá por el resto de su vida}

A principios de 1895 emigró hacia la Argentina, arribando a Buenos Aires, junto con su hija Aspasia y Clorinda Matto, esta última una fervorosa cacerista, ese viaje fue un nuevo autoexilio político, esta vez relacionado con el derrocamiento del general Cáceres. ${ }^{6,13,37,38}$

Ello también obligó el destierro de la familia de aquel militar, así Zoila Aurora, su tercera hija, llegó a Buenos Aires, donde participó en la vida intelectual porteña, escribiendo para diversas publicaciones, entre ellas las revistas Búcaro Americano y La Filosofía Positiva, fundadas por Matto y Muñoz respectivamente. $^{38,39}$ En 1898 también llegó Mercedes Cabello, pero sólo para participar en el Congreso Internacional Pedagógico. ${ }^{38}$

Muñoz y Matto instalaron en Buenos Aires la Logia Femenina el 8 de marzo de $1895^{6,40}$, siendo su relación con la masonería argentina estrecha y perdurable, incluso Margarita llegó a ser consejera honorífica del Supremo Concejo del Rito Ecléctico del Río de la Plata, fundado en $1894^{41}$, designación particularmente honrosa por su condición de mujer y extranjera.

Entre junio y diciembre de 1898 dirigió La Filosofía Positiva, una revista que sólo tuvo seis números y en la que se difundieron las ideas de August Comte, publicándose fragmentos de las obras de dicho autor y manuscritos de sus compatriotas Juan Francisco Robinet, Ernesto Delbet y Paul Ritti, los argentinos José Ingenieros, Alfredo Palacios, Máximo Sabá Victoria, Enrique de Santa Olalla, Felipe Senillosa y Luis Mohr, y el chileno Juan Lagarrigue entre otros. ${ }^{6,42}$
En su breve pero intensa vida, esta revista fue la caja de resonancia de varios procesos políticos argentinos e internacionales, así apoyó la campaña del Comité Liberal para solicitar a la Convención Constituyente, reunida en Buenos Aires, la separación de la Iglesia y el Estado, y denunció al gobierno de la provincia de Tucumán por destituir a Máximo Victoria, Inspector General de Escuelas, a causa de su acción progresista, la cual generó gran resistencia en la iglesia local. ${ }^{42,43}$

En este tiempo Margarita empezó su paulatino apartamiento del pensamiento comtiano sobre el papel de la mujer en la sociedad, esa brecha expuesta en La evolución de Paulina se fue ampliando a medida que se involucró más en el ámbito del liberalismo librepensador y anticlerical en Buenos Aires. $^{6}$

En Argentina publicó los opúsculos Dos mártires del librepensamiento (Buenos Aires, 1895), Sobre las doctrinas de Augusto Comte. Respuesta al señor Mariano José Madueño (Buenos Aires, 1896), Sobre las doctrinas de Augusto Comte. Segunda carta al señor Mariano José Madueño (Buenos Aires, 1896), Devuelvo el obsequio y formulo mi profesión de fe liberal (Buenos Aires, 1907), y La Novela de Juliano por Dimitry Merejkowsky. Cuatro palabras a los intelectuales (Buenos Aires, 1908).

También escribió los libros Mis primeros Ensayos (Buenos Aires, 1902), Las cartas y conferencias cientificas (Montevideo, 1905) y Las calamidades del presente. Estudio crítico y filosófico del momento actual (Santiago del Estero, 1908). Igualmente es significativo su artículo Algo sobre la señorita Henríquez, publicado en 1902, en el que recordaba la gesta de aquella dama cuzqueña. Mis primeros ensayos contienen dieciséis manuscritos sobre diversos temas, la mayoría anteriores de su partida a Chile, cuyo prólogo titulado Cuatro Palabras fue obra de Mariano José Madueño, militar peruano exiliado ${ }^{44}$ y tenaz opositor de Piérola, que se publicó años después 
de su arribo a Buenos Aires. ${ }^{34}$ Allí quedó clara su adhesión al positivismo y su irreductible posición laicista y anticlerical, que siempre diferenció rotundamente de la fe católica y de la creencia en Dios; igualmente, proyectó su personalidad creativa y perspectiva de científica, propias de una mujer intelectual consciente del maltrato de las instituciones hacia su género, aunque con el optimismo de avizorar un mejor porvenir. ${ }^{34}$

Su formación científica materialista no le impidió acercarse al ámbito de la teosofía y convertirse en miembro de la Sociedad Teosófica en Argentina, así en La Filosofía Positiva insertó textos teosóficos, a primera vista poco compatibles con la ortodoxia comteana. ${ }^{45}$

En 1902 se trasladó a Montevideo (Uruguay), integrándose a la Sociedad Teosófica de aquel lugar. ${ }^{13,45}$ En el Ateneo de esa ciudad pronunciaría la disertación La Ciencia Esotérica de Oriente, partiendo del análisis de la antigua religión védica hindú, explicando cómo en distintas vertientes del pensamiento antiguo podían encontrarse intuiciones o aproximaciones hacia una verdad superior que condensaba el Alma Universal, que sólo podía presentarse a la humanidad como revelaciones transmitidas en el lenguaje de las religiones y toscas creencias que los hombres ideaban para explicar lo incognoscible. $^{13}$

Eneste periodoteosófico intensificóla revalorización del cristianismo, así en la conferencia Desarrollo progresivo de la autoridad espiritual del mundo Antiguo sostuvo que en la antigüedad clásica y preclásica, fue la formación de una casta sacerdotal la que galvanizó a la sociedad con sus enseñanzas y su guía moral que fortalecían todo el cuerpo social. ${ }^{13}$ En 1905 regresó a Buenos Aires y posteriormente emigró a la provincia de Santiago del Estero, donde trabajó en los obrajes de los quebrachales, negocio que se basaba en la explotación del árbol denominado quebracho, abundante en aquel lugar, que era muy apreciado por su madera y el alto contenido de taninos, unas sustancias orgánicas que se utilizaban para convertir las pieles de los animales en cuero. ${ }^{13}$

En 1907 Muñoz publicó el folleto Devuelvo el obsequio y formulo mi profesión de fe liberal, que inició comentando un suelto de prensa que la calificó como librepensadora, que no aceptaba y señalaba que los móviles y objetivos que encarnó el librepensamiento como corriente de ideas y como movimiento ya se habían alcanzado, ya que la libertad de pensamiento estaba plenamente asegurada en el mundo moderno. ${ }^{13}$

El 25 de octubre de 1908 el Congreso Nacional del Perú aprobó la Ley $N^{\circ} 801$, entre cuyos firmantes estaba el doctor Ramón Hermegildo David Matto Usandivaras, secretario del Senado, médico y hermano de Clorinda, que poco después, el 7 de noviembre de 1908, fue promulgada durante el primer gobierno de Augusto B. Leguía, que en su artículo único decía: "Las mujeres que reúnan los requisitos que la ley exige para el ingreso a las universidades de la República, serán matriculadas en ellas cuando así lo soliciten, pudiendo optar los grados académicos y ejercer la profesión a que se dediquen". 8

Esta ley hizo justicia a la larga lucha por la igualdad y derecho a la instrucción de las peruanas iniciada medio siglo antes por un grupo de damas ilustradas, proceso en el que nuestra biografiada tuvo una activa e importante participación; lamentablemente apenas faltaban algo más de dos meses para que la vida de Margarita se apagara para siempre.

También en 1908 publicaba su último libro titulado Calamidades del Presente, que se editó en Santiago del Estero, donde las referencias a los autores católicos incluyeron a Lamennais, Enrique Sienkiewicz, Cantú, al abate Constant y el Conde De Maistre; allí describía un cuadro pavoroso que denominó "la disolución, el libertinaje y la anarquía reinantes", que se refería a la Argentina de aquel 
entonces, donde los conflictos sociales habían adquirido características insurreccionales. ${ }^{13}$

Ante lo que consideraba el advenimiento de una época de desorden y decadencia repartía mandobles a diestra y siniestra contra los científicos ateos, los anarquistas, las mujeres frívolas, los anticlericales rabiosos y hasta con los escritores románticos y naturalistas como Muset, George Sand, Balzac y Zola. ${ }^{13}$

$\mathrm{Su}$ pensamiento evolucionó de la ortodoxia comtiana al feminismo librepensador; y, la teosofía y el cristianismo alternativo serían también corrientes de interés para ella. ${ }^{46}$

\section{EI final de la vida terrenal}

Margarita falleció el 21 de enero de 1909, en la ciudad de Añatuya, un pueblo que hoy en día es la cabecera del departamento General Taboada, en la provincia de Santiago del Estero, Argentina, y que a principios del siglo XX era un lugar inhóspito y lleno de carencias materiales. ${ }^{6}$

El deceso motivó algunas notas en la prensa argentina y extranjera, así la revista montevideana Apolo, dedicada al arte y la sociología, reseñaba: "Ha muerto también en uno de los pueblos del interior de Argentina, la distinguida escritora y médica peruana Margarita Práxedes Muñoz", y más adelante señalaba: "deja un vacío en el mundo literario, muy difícil de llenar, hoy, que en la lucha por la vida, cada vez más cruenta, claudican verdaderos cruzados del Ideal Liberal y de la falange acrática". ${ }^{47}$

Fue una de las cinco mujeres que ejercieron la medicina en Argentina durante el siglo XIX, tres eran oriundas de aquel país: Cecilia Grierson, Petrona Eyle y Elvira Rawson Guiñazú. La cuarta fue Rosa Pavlosky, de nacionalidad rusa, y la quinta nuestra compatriota. ${ }^{12}$ Sólo dos de ellas -Grierson y Rawson- estudiaron en dicho país, lo que demuestra las dificultades que tenían las féminas para acceder a los estudios superiores. ${ }^{2}$

\section{Luego de su muerte}

En 1910, Dora Mayer escribía un breve ensayo titulado La intelectualidad femenina en el Perú, en la que la mencionaba escueta y simplemente como una "joven bonita y amante del estudio". ${ }^{48}$

En 1925, Elvira García y García dijo "no fue correspondida como merecía su potencia intelectual, tan rica y espontánea. Acabó sus últimos días en Buenos Aires, lejos de los suyos, y olvidada de sus compatriotas, que nada hicieron en su obsequio". ${ }^{9}$ Esta glosa aparece en el segundo tomo de su obra La mujer peruana a través de los siglos, como parte de la biografía de Margarita, insertada en la sección La Mujer en la Facultad de Letras, y donde hay un equívoco respecto al lugar de su óbito. ${ }^{9}$

En 1951, el médico e historiador Juan Bautista Lastres publicó en tres tomos la Historia de la Medicina Peruano, en cuyo tercer volumen, sobre la época republicana, no le dedicó ni una sola línea a nuestra biografiada. ${ }^{49}$ Igualmente, fue ignorada por gran parte de los historiógrafos de la ciencia galénica del Perú.

También en 1951, al celebrarse el cuarto centenario de la Universidad Nacional Mayor de San Marcos, su Alma Mater, Luís Antonio Eguiguren Escudero, abogado, político e historiador piurano, publicó el libro La Universidad Mayor de San Marcos. IV Centenario de la fundación de la Universidad Real y Pontificia y de su vigorosa continuidad histórica, en el cual igualmente omitió cualquier mención sobre Margarita. ${ }^{50}$

El viernes 8 de octubre de 2010 se fundó en la ciudad de Lima, la Gran Logia Femenina del Perú, algo más de ciento quince años después de la que Muñoz y otras damas peruanas establecieron en Buenos Aires. La Gran Logia del Perú, que hacía 
fines del siglo XIX había alentado una forma estable de asociación femenina en la masonería, tuvo un corto aliento en ese empeño, ya que Christian Dam, gran maestre electo para el período 1896 a 1897, al dejar el cargo se retiró de la actividad masónica para dedicarse de lleno al activismo librepensador. ${ }^{19,51}$ Tras su partida, los masones abandonaron toda preocupación por promover la masonería entre las mujeres. ${ }^{27}$

En 2017, el Congreso de la República acordó saludar a la Gran Logia Femenina del Perú con motivo de su séptimo aniversario, en uno de los considerandos de dicho saludo se recordó a Margarita y otras precursoras: "son dignas representantes de las mujeres masonas peruanas por su aporte a la sociedad, doña Flora Tristán, Clorinda Matto de Turner, Margarita Práxedes Muñoz, Antonia Moreno de Cáceres, Zoila Aurora Cáceres, María Jesús Espinoza, Juana Alarco de Dammert, Teresa Gonzáles de Fanning, entre otras destacadas mujeres masonas". ${ }^{52}$

Entre julio y setiembre de 2019, fue parte de la muestra De la literatura a la historia. Las intelectuales del primer centenario de la República, organizada en el Centro Cultural Inca Garcilaso de la Vega del Ministerio de Relaciones Exteriores, en la que se rindió homenaje a las peruanas que cuestionaron "los roles sociales asignados por la clase en el poder, y bajo una luz crítica manifiesta en el ejercicio periodístico y el quehacer literario, abrió un nuevo camino para la liberación femenina". ${ }^{53}$

Uno de los pocos recuerdos que existen de ella en su Lima natal es una pequeña calle nombrada con su nombre en la Urbanización Pando, en el distrito de San Miguel.

\section{Epílogo}

Margarita Práxedes Muñoz estuvo muy lejos de los paradigmas sociales imperantes en América Latina y el Perú del siglo XIX, esta conducta contracultural le valió críticas, descrédito y ostracismo en su patria, de la que se alejó definitivamente para vivir sus últimos veinte años en ambientes sociales más propicios para el desarrollo personal, intelectual y político.

Esa distancia geográfica, en un mundo absolutamente ajeno a la globalización, le granjeó el gran desafecto de los círculos intelectuales conservadores de Lima, que contribuyó a que su imagen se perdiera en el olvido y quedara inédita para la inmensa mayoría de sus compatriotas, entre ellos los miembros de la orden médica peruana. Sólo en los últimos tiempos mereció ser rescatada por algunos autores peruanos y extranjeros, entre los que nos sumamos como una obligación moral y un acto de estricta justicia histórica.

\section{Referencias bibliográficas}

1. Cevasco G. La educación, clave para la autonomía de las mujeres. Tarea. 2016; (91):64-8.

2. Palermo A. Mujeres Profesionales que Ejercieron en Argentina en el Siglo XIX. Convergencia. 2005; 12(38):59-79.

3. Martínez A. Del masculino pasado al femenino futuro: mujer, historia y medicina. Rev Salud hist sanid. 2007; 2(3):5-20.

4. Jiménez A. Doctora Eloísa Díaz Insunza. Rev Chil Infect. 2000; 17(1):76-8.

5. Sánchez K. El ingreso de la mujer chilena a la universidad y los cambios en la costumbre por medio de la ley 1872-1877. Historia. 2006; 39(2):497-529. doi: http://dx.doi.org/10.4067/S071771942006000200005 .

6. Valladares O. La incursión de las mujeres a los estudios universitarios en el Perú: 1875-1908. Cuadernos del Instituto Antonio de Nebrija. 2012; 15(1):105-23.

7. C.L.S. Algo para una ley de instrucción o sean apuntaciones sobre los medios de mejorar la instrucción pública del Perú. Lima: Imprenta Liberal de El Correo del Perú; 1874. p. 163.

8. Vidal G. Apuntes sobre el reconocimiento del derecho a la educación superior a las mujeres. Unife. 2012; (18):66-74.

9. García E. La mujer peruana a través de los siglos. Tomo 2. Lima: Imprenta Americana; 1925. p. 387, 389, 457, 459, 463-465.

10. Valdivia M. El feminismo católico peruano: avances, controversias y paradojas entre 1930-1956 (Tesis de maestría en Historia). Porto Alegre, Brasil: Universidad Federal de Río Grande do Sul. 2016. p. 69.

11. Berra H. Francisca Montaut de Osuna: primera médica graduada en la Facultad de Medicina de Rosario. Rev Med Rosario. 2012; (78):14552.

12. Goswitz M. Escritores y ensayistas: hacia el rescate y la dignificación de la ensayística femenina en la prensa (Tesis doctoral en Filología). Madrid, España: Universidad Nacional de Educación a Distancia (UNED). 2018. p. 44, 45, 51, 52, 57, 166.

13. De Lucía D. Margarita Práxedes Muñoz, visión del alba y el ocaso. El 
Catoblepas. 2009; 83

14. Wurst V. Lo velado de las veladas literarias de Juana Manuela Gorriti: la construcción del sujeto femenino en el siglo XIX (Tesis de licenciatura en Lingüística y Literatura). Lima, Perú: Pontificia Universidad Católica del Perú; 2015. p. 4, 29.

15. Gorriti J. Veladas literarias de Lima 1876-1877. Tomo 1. Buenos Aires: Imprenta Europea; 1892. p. IX-XLI.

16. Obligado P. Juana Manuela Gorriti. Buenos Aires: Imprenta de M. Biedma; 1878. p. III-XVII.

17. Bromley J. Las viejas calles de Lima. 1 ra edición. Lima: Municipalidad Metropolitana de Lima; 2019. p. 117, 151, 272.

18. Oré H. Clorinda Matto de Turner. Una masona en su tiempo. Lima: Gran Logia del Perú; 2014. p. 70, 102.

19. Cornejo C. El pensamiento de las mujeres ilustradas y la educación femenina en el debate de laicización del Estado peruano decimonónico (1870 - 1899) (Tesis doctoral en Educación). Lima, Perú: Universidad de San Martín de Porres; 2014. p. 253.

20. Tauro A. Clorinda Matto de Turner y la novela indigenista. Lima: Universidad Nacional Mayor de San Marcos; 1976. p. 5.

21. Quiroz R. Margarita Práxedes Muñoz: una aventura intelectual luminosa (1893). Lima: Universidad Nacional Mayor de San Marcos; 2014. p. 9, 13-15.

22. Tauzin-Castellanos I. El positivismo peruano en versión peruana: Mercedes Cabello de Carbonera y Margarita Práxedes Muñoz. BAPL. 1996; 27:79-100.

23. Pachón D. Del pensamiento neocolonial a la filosofía de la liberación latinoamericana. Cuadernos Canela. 2017; (28):49-63.

24. Díaz C. Barranca. El sabio olvidado. Primera edición. Lima: Litho \& Arte SAC; 2013. p. 161, 231, 297.

25. Galindo J. Memoria que presenta el Ministro de Justicia, Culto, Instrucción y Beneficencia al Congreso Ordinario de 1890. Lima: Imprenta Torres Aguirre; 1890. p. 11.

26. Práxedes M. Unidad de la materia o identidad sustancial de los reinos inorgánico y orgánico. Tesis de bachiller, Facultad de Ciencias, Universidad Mayor de San Marcos. Lima: Imprenta Juan M. Gall; 1890. p. 3.

27. Chocano M. Lima masónica: las logias simbólicas y su progreso en el medio urbano a fines del siglo XIX. Revista de Indias. 2010; 70(249):409-44.

28. Margarita Práxedes Muñoz. El Perú Ilustrado. 1890; 4(181):994.

29. T. Ófilo. Un viejo doctor. La Prensa Libre. Lima, 16 de diciembre de 1890. p. 1.

30. Aranda R. Leyes y resoluciones expedidas por el Congreso Ordinario de 1890. Lima: Imprenta del Universo; 1891. p. 163, 164.

31. Diario de los debates de la H. Cámara de Senadores. Congreso Ordinario 1891. Lima: Imprenta de El Comercio; 1891. p. 754.

32. Nuevos socios. La Crónica Médica. 1890; 7(78):171.

33. Glave L. Letras de Mujer. Juana Manuela Gorriti y la imaginación nacional andina, siglo XIX. Fractal. 1996; 1(3):93-125.

34. Rojas L. Margarita Práxedes Muñoz: E pluribus unum o hacia una República unida. Tinku. 2015; (23):5-19.

35. Ramírez V. Las mujeres y la divulgación de la ciencia en Chile: mediadoras de la circulación del saber en revistas culturales (18701900). Meridional. Revista Chilena de Estudios Latinoamericanos. 2019; 13:15-40. doi: 10.5354/0719-4862.54415

36. López H. Sucedió hace un siglo. Segunda parte. Lima: Editorial e imprenta DESA S.A.; 1996. p. 207.

37. Matto C. Herencia. Primera edición. Buenos Aires, Argentina: Stockcero; 2006. p. XV, XVIII.

38. Vicens M. La fantasía porteña: escritoras peruanas en la Buenos Aires de entre siglos. RIRA. 2018; 3(1):77-111.
39. Miseres V. Modernismo puertas adentro: género, escritura y experiencia urbana en Mi vida con Enrique Gómez Carrillo de Aurora Cáceres. Modern Languaje Notes. 2016; 131(2):398-417.

40. De Lucía D. La antorcha del progreso por los caminos del sur. Los espacios positivistas en la Argentina y su proyección iberoamericana (1895-1900). Cuyo. 1997; (14):77-113.

41. Darrigran G. La Gran Logia Bonaerense y su preocupación por la educación: Una de las fuentes del rito nacional español. REHMLAC. 2017; 9(1):28-55.

42. Victoria M. Máximo Sabá Victoria. En: Sitiales. Santiago del Estero, Argentina: Lucrecia Editorial; 2010. p. 107.

43. Jugo Suárez A. La organización escolar en Santiago del Estero, entre Caseros y la formación del Estado Nación, 1859-1882. Antigua Matanza. Revista de Historia Regional. 2018; 2(3):10-33.

44. Holguín O. Los peruanos y el exilio español en los siglos XIX y XX. Revista de Estudios Colombinos. 2008; (4):75-90.

45. Quereilhac S. La imaginación científica. Ciencias ocultas y literatura en el Buenos Aires de entre siglos (1875-1910) (Tesis doctoral en Filosofía y Letras). Buenos Aires, Argentina: Universidad de Buenos Aires; 2010. p. 184, 185.

46. Ferrús B. Cuando las "obreras del pensamiento" escriben de amor: Juana Manso, Carlota Garrido de la Peña y Mercedes Práxedes Muñoz. Anales de Literatura Hispanoamericana. 2014; (43):255269.

47. Margarita Práxedes Muñoz. Apolo. 1909; 4(25):79.

48. Mayer D. La intelectualidad femenina en el Perú. En: Poirier E (editor). Chile en 1910. Santiago de Chile: Imprenta, litografía y encuadernación Barcelona; 1910. p. 400-407.

49. Lastres J. Historia de la Medicina Peruana. La Medicina en la República. Volumen III. Universidad Nacional Mayor de San Marcos. Lima: Imprenta Santa María; 1951.

50. Eguiguren L. La Universidad Mayor de San Marcos. IV Centenario de la fundación de la Universidad Real y Pontificia y de su vigorosa continuidad histórica. Lima: Imprenta Santa María; 1951.

51. Hilario J. Del radicalismo liberal al anarquismo: vidas paralelas de Christian Dam y Manuel González Prada. Desde el Sur. 2018; 10(1):177-197. doi: 10.21142/DES-1001-2018-177-197

52. Congreso de la República. Moción de Orden del Día N ${ }^{\circ} 3705$. Saludo por el séptimo aniversario de la Gran Logia Femenina del Perú. Lima, 4 de octubre de 2017.

53. De la literatura a la historia. Las intelectuales del primer centenario de la República. Lima: Centro Cultural Inca Garcilaso de la Vega, Ministerio de Relaciones Exteriores; 2019. p. 2, 4.

\section{Correspondencia:}

Ricardo Álvarez-Carrasco ralvarezcarrasco@yahoo.com

Fecha de recepción: 15-04-2021.

Fecha de aceptación: 20-08-2021.

Contribuciones de autoría: El autor ha participado en la concepción y diseño, recolección bibliográfica, redacción del manuscrito y revisión del mismo.

Financiamiento: por el autor.

Declaración de conflictos de interés: ninguno, según el autor. 